\title{
Trastuzumab emtansine is active on HER-2 overexpressing NSCLC cell lines and overcomes gefitinib resistance
}

\author{
Daniele Cretella ${ }^{1 \dagger}$, Francesca Saccani ${ }^{1 \dagger}$, Federico Quaini ${ }^{1}$, Caterina Frati ${ }^{1}$, Costanza Lagrasta ${ }^{2}$, Mara Bonelli ${ }^{1}$, \\ Cristina Caffarra ${ }^{1}$, Andrea Cavazzoni ${ }^{1}$, Claudia Fumarola ${ }^{1}$, Maricla Galetti ${ }^{1,3}$, Silvia La Monica ${ }^{1}$, Luca Ampollini ${ }^{4}$, \\ Marcello Tiseo ${ }^{5}$, Andrea Ardizzoni ${ }^{5}$, Pier Giorgio Petronini ${ }^{1}$ and Roberta R Alfieri ${ }^{{ }^{*}}$
}

\begin{abstract}
Background: HER-2 represents a relatively new therapeutic target for non small cell lung cancer (NSCLC) patients. The incidence for reported HER-2 overexpression/amplification/mutations ranges from 2 to $20 \%$ in NSCLC. Moreover, HER-2 amplification is a potential mechanism of resistance to tyrosine kinase inhibitors of the epidermal growth factor receptor (EGFR-TKI) (about 10\% of cases). T-DM1, trastuzumab emtansine is an antibody-drug conjugate composed by the monoclonal antibody trastuzumab and the microtubule polymerization inhibitor DM1. The activity of T-DM1 has been studied in breast cancer but the role of T-DM1 in lung cancer remains unexplored.

Methods: Antiproliferative and proapoptotic effects of T-DM1 have been investigated in different NSCLC cell lines by MTT, crystal violet staining, morphological study and Western blotting. HER-2 expression and cell cycle were evaluated by flow cytometry and Western blotting. Antibody dependent cell cytotoxicity (ADCC) was measured with a CytoTox assay. Xenografted mice model has been generated using a NSCLC cell line to evaluate the effect of T-DM1 on tumor growth. Moreover, a morphometric and immunohistochemical analysis of tumor xenografts was conducted.

Results: In this study we investigated the effect of T-DM1 in a panel of NSCLC cell lines with different HER-2 expression levels, in H1781 cell line carrying HER-2 mutation and in gefitinib resistant HER-2 overexpressing PC9/HER2cl1 cell clone. T-DM1 efficiently inhibited proliferation with arrest in G2-M phase and induced cell death by apoptosis in cells with a significant level of surface expression of HER-2. Antibody-dependent cytotoxicity assay documented that T-DM1 maintained the same activity of trastuzumab. Our data also suggest that targeting HER-2 with T-DM1 potentially overcomes gefitinib resistance. In addition a correlation between cell density/tumor size with both HER-2 expression and T-DM1 activity was established in vitro and in an in vivo xenograft model.
\end{abstract}

Conclusions: Our results indicate that targeting HER-2 with T-DM1 may offer a new therapeutic approach in HER-2 over-expressing lung cancers including those resistant to EGFR TKIs.

Keywords: Lung cancer, HER-2, Trastuzumab, T-DM1

\footnotetext{
* Correspondence: roberta.alfieri@unipr.it

${ }^{\dagger}$ Equal contributors

'Department of Clinical and Experimental Medicine, University of Parma, Via Gramsci 14, 43126 Parma, Italy

Full list of author information is available at the end of the article
} 


\section{Background}

A number of molecular aberrations have been identified in non small cell lung cancer (NSCLC), including EGFR, BRAF, HER2 mutations, EML4-ALK, ROS1 and RET rearrangements in adenocarcinoma; FGFR mutations/amplifications, DDR2 or PIK3CA mutations in squamous cell carcinoma [1]. Conflicting results have demonstrated marginal benefit of targeted molecules in unselected populations of patients with advanced NSCLC. However, some targeted agents have been approved in different line settings for the treatment of specific subgroups of patients [2-5]. In particular, the epidermal growth factor receptor (EGFR) has been successfully targeted in NSCLC patients harbouring activating-EGFR mutations by small molecules inhibiting the tyrosine kinase domain (gefitinib, erlotinib and afatinib) [2-4]. Moreover, crizotinib has been approved by US Food and Drug Administration (FDA) and European Medicines Agency (EMA) for the treatment of advanced or metastatic ALK positive NSCLC patients $[5,6]$.

The acquisition of resistance to tyrosine kinase inhibitors (TKIs) in clinical oncology is a well documented phenomenon that applies to several types of cancers. Almost all NSCLC patients with activating EGFR mutations treated with EGFR-TKI, after an initial response, experience disease progression within 10 to 14 months from the beginning of the therapy [7]. A commonly described mechanism of drug resistance involves additional genetic alterations within the EGFR itself, the most frequent being the T790M mutation accounting for approximately $50 \%$ of cases of acquired resistance [8]. An additional well documented mechanism is MET amplification initially reported in $15-20 \%$ of resistant patients [9] but recently reduced to $3-5 \%[10,11]$. Several other pathways have been associated with resistance to EGFR TKI including histologically documented transformation to small phenotype, PIK3CA mutation and epithelial to mesenchymal transition [12].

HER-2 represents a relatively new therapeutic target for NSCLC. The potential clinical relevance of HER-2 expression in NSCLC is currently under evaluation [13], however, the recent role of HER-2 amplification in the acquisition of resistance to TKI, reported in $12-13 \%$ of patients $[11,14]$, may render HER-2 a potential target not only in breast cancer but also in NSCLC.

T-DM1, trastuzumab emtansine, is an antibody-drug conjugate composed by the microtubule polymerization inhibitor DM1 (derivative of maytansine) linked with a stable thioether linker to trastuzumab, a monoclonal antibody that targets HER-2 receptor [15]. After binding to HER-2 receptors, the complex undergoes internalization and lysosomal degradation with the release of DM1 active catabolites that bind to tubulin and suppress microtubule dynamics [16].

The activity of T-DM1 has been extensively studied in several human breast cancer cell lines $[15,17,18]$ showing a superior activity compared to trastuzumab in HER-2 overexpressing cells. T-DM1 has been recently approved for the treatment of HER-2-positive metastatic breast cancer patients previously treated with trastuzumab and taxane [19].

The aim of the present study was to test whether T-DM1 activity is affected by HER-2 expression/mutation status and may overcome EGFR-TKI resistance in NSCLC cell lines. To this purpose we evaluated the effect of T-DM1 in a panel of NSCLC cell lines with different HER-2 expression levels, in H1781 cell line carrying HER-2 mutation [20], and in gefitinib resistant HER-2 overexpressing PC9/HER2cl1 cell clone [14]. Moreover, we explored the correlation between cell density/ tumor size, HER-2 expression and T-DM1 activity in vitro and in an in vivo xenograft model.

\section{Results}

HER-2 expression level in human non-small-cell lung cancer cell lines

The total level of HER-2 protein was detected by immunoblotting on cell lysates in a panel of NSCLC cell lines (H1781, H3255, H322, H1299, H1975, Calu-6, H596, H460, A549, PC9, HCC827 and Calu-3). As shown in Figure 1A, HER-2 expression varied widely among the analyzed cell lines, ranging from barely detectable levels in Calu-6 to high levels in Calu-3. The latter was an expected finding, due to known amplification of HER-2 in Calu-3 cell line [21]. Considering that trastuzumab and T-DM1 have a common targeted receptor on the cell surface, we quantified HER-2 expression levels on the plasma membrane by flow cytometry. Indeed, the ability of the antibody to interact with its target is strictly related to the presence of the receptor on the cell surface. As reported in Figure 1B, Calu-3 and H3255 cells displayed the highest levels of HER-2 at the plasma membrane. The total level of HER-2 in H3255 was similar to that observed in other cell lines such as H460 and A549 (Figure 1A) indicating that the total level of proteins detected on cell lysate is not a good predictor of HER-2 level on plasma membrane.

\section{Effect of T-DM1 and trastuzumab treatment on cell viability of NSCLC cell lines with different HER-2 expression}

Based on the previous analysis, the effect of T-DM1 and trastuzumab on cell viability was focused on NSCLC cell lines expressing different cell surface levels of HER-2: Calu-3 (very high), H3255 (high) and Calu-6 (low). T-DM1 showed strong anti-proliferative effect in HER-2 over-expressing Calu-3 cells $\left(\mathrm{IC}_{50}=0.40 \pm 0.08\right.$ $\mu \mathrm{g} / \mathrm{ml}$, Figure $1 \mathrm{C}$ ), whereas no effects were detected on Calu- 6 cell line, with low levels of HER-2 on the plasma membrane. The inhibition observed at $10 \mu \mathrm{g} / \mathrm{ml}$ was related to a non-specific toxic effect of T-DM1, as previously 


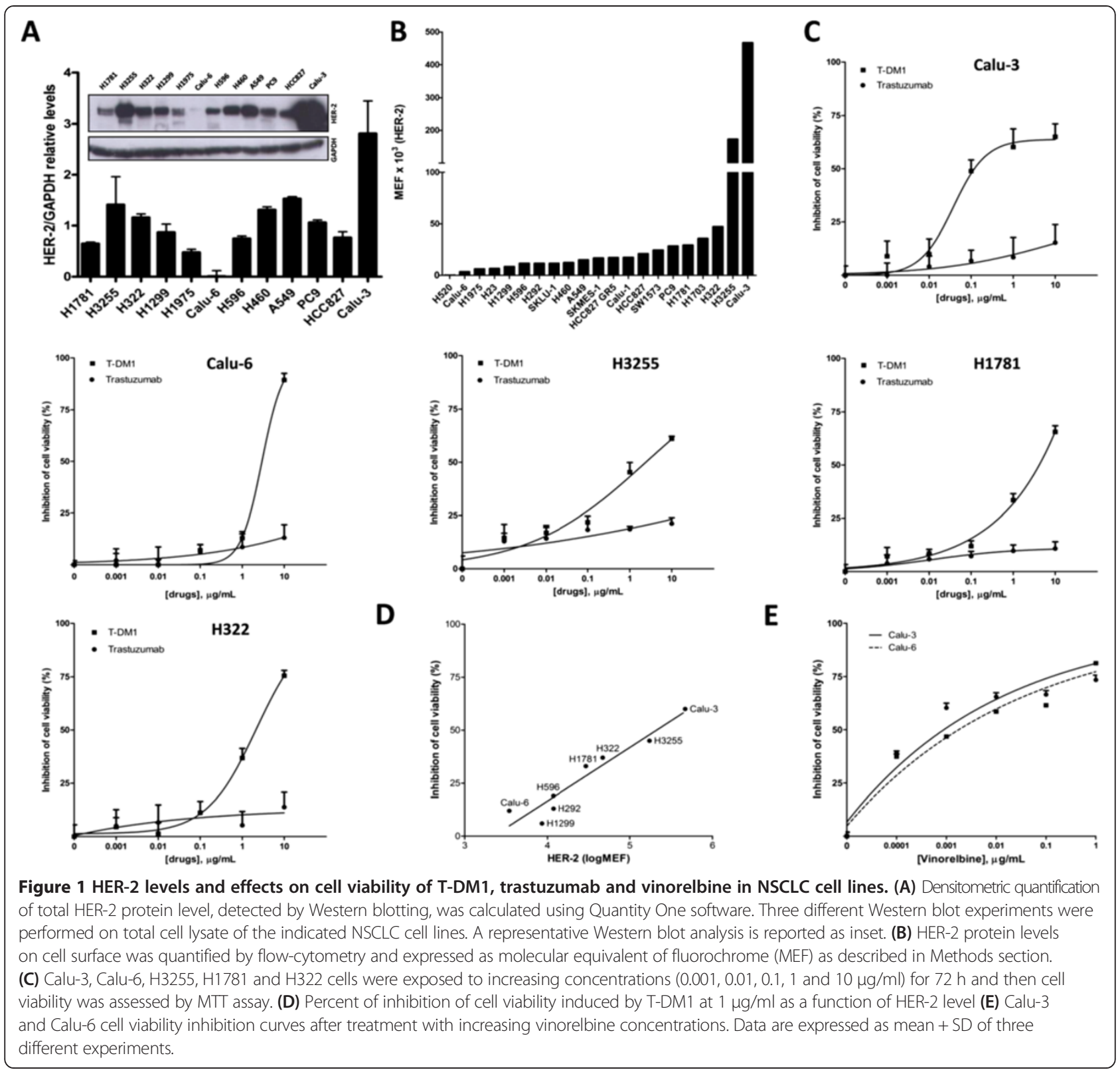

reported in MCF-7 HER-2 negative breast cancer cell line [22]. Intermediate results were seen on H3255 cells. Trastuzumab, administered at the same dosages of T-DM1, did not show notable effect on cell growth in any of the cell lines tested. H1781 cell line, harbouring mutated HER-2 (G776insV_G/C), was also included in this study in order to investigate whether this mutation influenced the anti-proliferative effect of T-DM1. As shown in Figure 1C, T-DM1 at $1 \mu \mathrm{g} / \mathrm{ml}$ induced about 35\% inhibition of cell viability. A similar inhibition profile was observed in T-DM1 $(1 \mu \mathrm{g} / \mathrm{ml})$ treated H322 cells, displaying comparable levels of HER-2 on cell surface (Figure 1B), suggesting that H1781 sensitivity to the drug is not affected by the mutated receptor. We then analyzed the percentage of inhibition of cell viability induced by $1 \mu \mathrm{g} / \mathrm{ml}$ T-DM1 on eight different cell lines, as a function of HER-2 level on plasma membrane and, as shown in Figure 1D, we confirmed that sensitivity to T-DM1 is strictly correlated to HER-2 expression on the cell surface.

To exclude the hypothesis that different effects of T-DM1 could be ascribed to dissimilar sensitivity to the microtubule polymerization inhibitor DM1, we treated two cell lines harbouring high and low levels of HER-2 on the plasma membrane, respectively Calu-3 and Calu-6, with increasing concentration of Vinorelbine, an anti-mitotic drug, which acts by a similar mechanism of action of the maytansinoid DM-1. Vinorelbine inhibited viability of Calu-3 and Calu-6 cells in a comparable manner (Figure 1E). 
Effect of T-DM1 and trastuzumab treatment on cell cycle distribution, signal transduction, cell death and antibody dependent cell cytotoxicity (ADCC)

To determine the effect of T-DM1 on cell cycle, Calu-3 treated with $1 \mu \mathrm{g} / \mathrm{ml}$ T-DM1 or Trastuzumab for $24 \mathrm{~h}$ were analyzed by flow cytometry. As shown in Figure 2A, T-DM1 caused an increase in the proportion of cells in G2-M phase with a decrease in G1 and S phases, whereas no alterations on cell cycle distribution were detected in cells treated with trastuzumab. The arrest of Calu-3 in G2-M phase of the cell cycle, as a result of T-DM1 exposure, was also supported by increased levels of Cyclin B1 as measured by western blot analysis (Figure 2B) whereas pRb and Cyclin A were unchanged.

We then tested the effect of T-DM1 and trastuzumab on phosphorylation status of HER-2, AKT and p42-44 MAPK in Calu-3 cell line. Differently of trastuzumab, T-DM1 significantly inhibited the phosphorylation of AKT and p42-44 after $24 \mathrm{~h}$ of treatment (Figure 2C) with a decrease in HER-2 total level and phosphorylation at $48 \mathrm{~h}$.

T-DM1 $(1 \mu \mathrm{g} / \mathrm{ml})$ exerted a significant cytotoxic effect already after $24 \mathrm{~h}$ of treatment, with appearance of floating dead cells (Figure 3A). By contrast trastuzumab did not modify cell proliferation nor induced cell death up to $72 \mathrm{~h}$ of treatment.

As shown in Figure 3B, $48 \mathrm{~h}$ exposure of Calu-3 cells to T-DM1 at 0.1 and $1 \mu \mathrm{g} / \mathrm{ml}$ induced the activation of caspases-7 and -9 and the release of cytochrome- $c$ into the cytoplasm (Figure 3C) indicating that the intrinsic pathway is involved in T-DM1-triggered apoptotic cell death. Vinorelbin was used as internal control. A lower activation of caspases and a weak release of cytochrome- $c$ was also induced by trastuzumab treatment even if no significant cell death was observed (Figure 3A).

Since antibody-dependent cell-mediated cytotoxicity (ADCC) is one of the main mechanisms of action of specific mAbs directed to ErbB family members in vivo [23], we examined whether the capability to activate natural killer (NK)-mediated ADCC is preserved by T-DM1. As shown in Figure 3D, T-DM1-dependent cytotoxicity in the presence of IL-2 activated NK cells was similar to trastuzumab-dependent cytotoxicity in Calu-3 overexpressing HER-2. In the low HER-2 expressing H1299 cells, neither T-DM1 nor trastuzumab significantly induced mAb-dependent cytotoxicity.
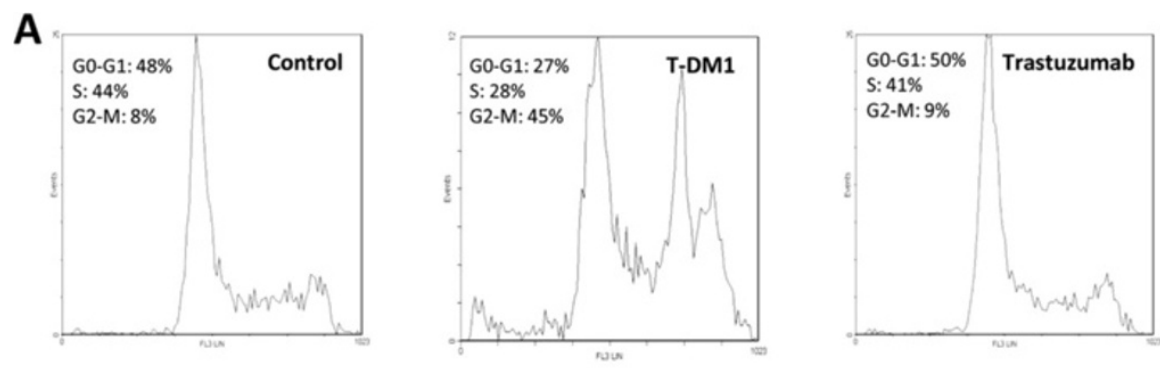

B

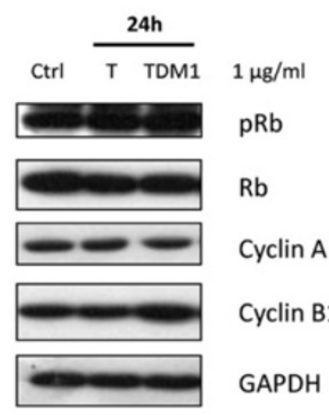

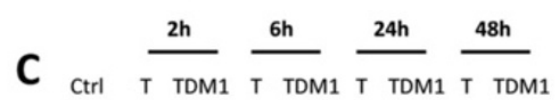

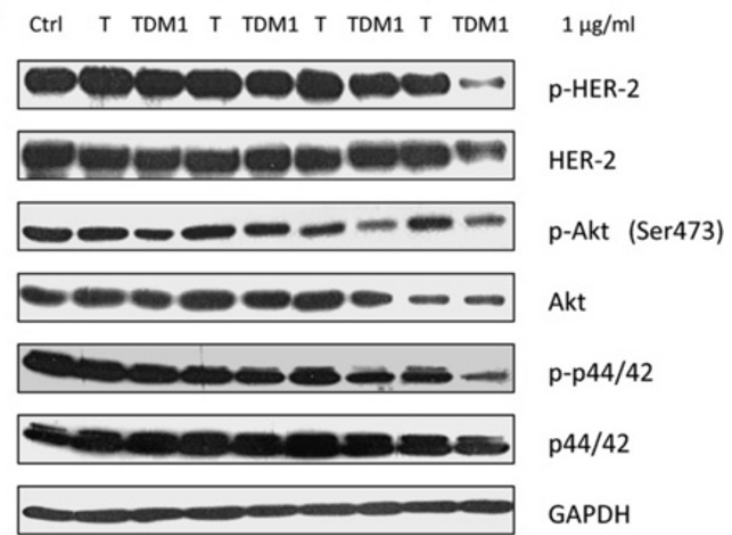

Figure 2 Influence of trastuzumab and T-DM1 on cell cycle phase distribution and cell signalling. (A) Calu-3 cells were cultured in the absence of drugs or treated either with T-DM1 or trastuzumab $(1 \mathrm{\mu g} / \mathrm{ml})$. After $24 \mathrm{~h}$ cells were stained with propidium iodide an cell-cycle-phase distribution was determined by flow cytometry analysis. Cell-cycle distributions were analyzed as described in Methods section and data were expressed as percentage of distribution in each cell-cycle phase. Immunoblot analysis on protein involved in cell cycle regulation (B) or signalling pathways $\mathbf{( C )}$ were conducted on cell lysates obtained after treatment with trastuzumab or T-DM1 $(1 \mathrm{\mu g} / \mathrm{ml})$ for the indicated period of time. 

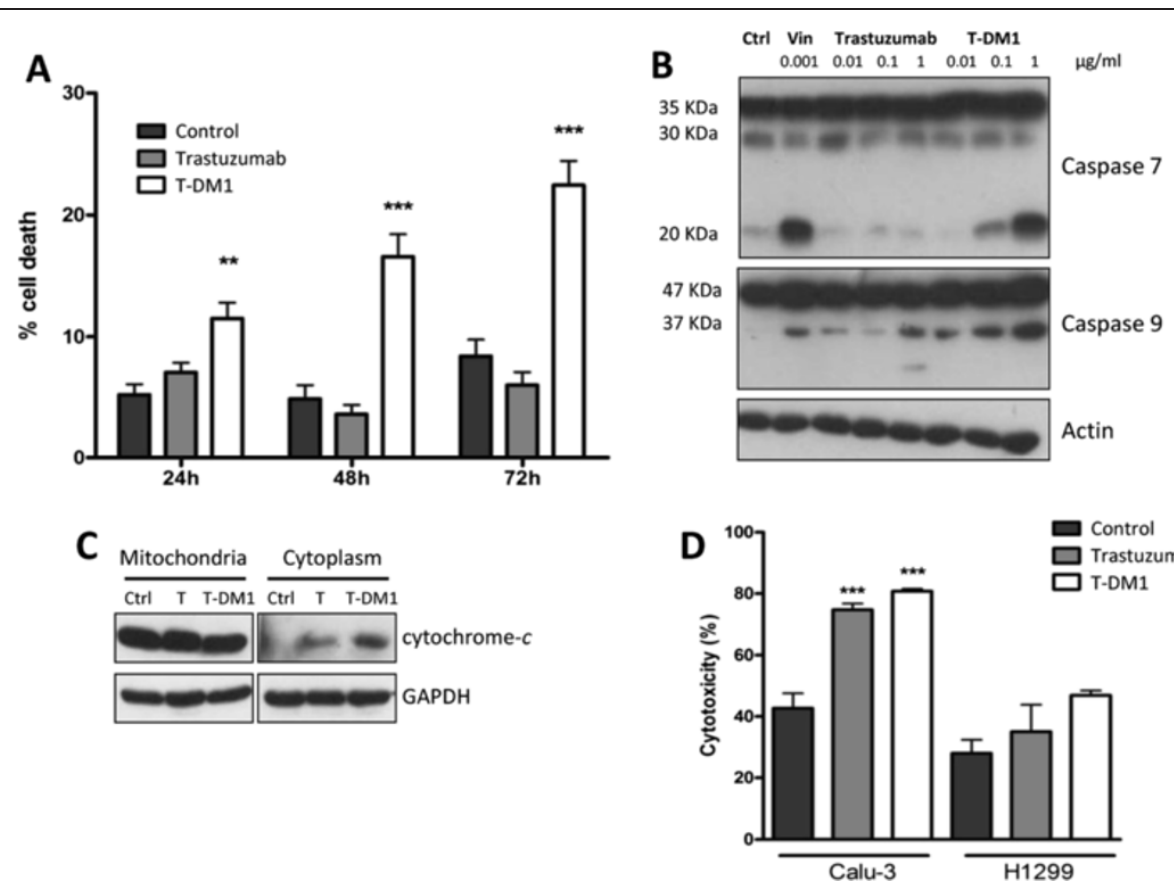

Figure 3 Effect of trastuzumab and T-DM1 on cell death and antibody dependent cell cytotoxicity. (A) Dead cells were counted after 24 48 and $72 \mathrm{~h}$ of exposure to trastuzumab or T-DM1 $(1 \mu \mathrm{g} / \mathrm{ml})$ and the percentage of dead cells was calculated. $\left({ }^{* *} \mathrm{p}<0.01\right.$, ${ }^{* * *} \mathrm{p}<0.001$ versus control, one-way ANOVA followed by Tukey's post-test). (B) Caspases 7 and 9 activation were detected by immunoblotting on cell lysates obtained after $48 \mathrm{~h}$ of Calu-3 exposure to increasing concentration of trastuzumab or T-DM1. Vinorelbine $0.001 \mu \mathrm{g} / \mathrm{ml}$ was used as positive control. (C) Cytochrome $c$ was detected in the cytoplasm by immunoblotting after $48 \mathrm{~h}$ of treatment with T-DM1 $1 \mu \mathrm{g} / \mathrm{ml}$ as described in Methods section. (D) Trastuzumab $(1 \mathrm{\mu g} / \mathrm{ml})$ or T-DM1 $(1 \mu \mathrm{g} / \mathrm{ml})$ were added to Calu-3 and H1299 cells seeded with $100 \mathrm{U} / \mathrm{ml} \mathrm{IL}-2$ activated-NK cells, at the ratio of 1:50. After $4 \mathrm{~h}$ lactate dehydrogenase release was quantified as described in Methods section and data expressed as percentage of cytotoxicity. The results are from representative experiments. The experiment, repeated three times, yielded similar results (***P $<0.001$, one-way ANOVA followed by Tukey's post-test).

\section{Effect of T-DM1 on EGFR-mutant PC9 cell line resistant to gefitinib for HER-2 overexpression}

As previously reported [14] and independently confirmed by our laboratory, the clone PC9/HER2c1 (a generous gift from Dr. William Pao), obtained by stably transfection of PC9 cells with HER-2 expression vector, is more resistant to gefitinib than parental cells. HER-2 expression on plasma membrane was 10 time higher in the clone compared to the parental cell line (data not shown).

Based on these results we tested the effect of T-DM1 on PC9/HER2c1 and in the parental PC9 cells. As shown in Figure 4A, HER-2 overexpression significantly enhanced the efficacy of T-DM1 with $40 \%$ inhibition of cell viability at $1 \mu \mathrm{g} /$ $\mathrm{ml}$ in the PC9/HER2c1 clone. With respect to PC9 cells, the clone showed a marked increase in AKT, p70S6K and p42-44 activation. After $48 \mathrm{~h}$ of treatment with T-DM1 a reduction in $\mathrm{AKT}$ and p70S6K phosphorylation was observed (Figure 4B) suggesting that T-DM1 might improve gefitinib treatment. In Figure $4 \mathrm{C}$ the dose-response curves of gefitinib in the presence of a fixed concentration of T-DM1 $(0.1 \mu \mathrm{g} / \mathrm{ml})$ are shown. Comparing the experimental combination points with that expected by the Bliss criterion, an additive effect was observed. In fact, no significant differences between experimental and theoretical points were observed.
In vivo activity of T-DM1 is dependent on tumor size and HER-2 expression

It has been reported that cell density can influence the expression of EGFR in breast cancer [24] and in pancreatic cancer cell lines [25] and that surface expression of HER-2 is regulated post-transcriptionally in mammary epithelial cells by the culture cell density [26]. We investigated the dependence of HER-2 membrane protein expression on cell density as well as the effect of T-DM1 on cells seeded at different densities. Confluent Calu-3 cells exhibited a significant decrease of HER-2 at cell surface level detected by immunohistochemistry (Figure 5A ii), as compared to cells seeded at low density (i). At low density, more than $80 \%$ of cells showed a strong surface expression of the receptor whereas in almost confluent Calu-3 cultures a significant downregulation of HER-2 was observed (nearly 35\%). Consequently, as reported in Figure 5B, the inhibition of cell viability induced by T-DM1 at $1 \mu \mathrm{g} / \mathrm{ml}$ was markedly decreased with increasing cell density.

We performed an in vivo experiment, aimed to determine whether T-DM1 efficacy might be affected by tumor size and structural organization. Tumors were clearly visible in all mice inoculated with $4 \times 10^{6}$ or $8 \times 10^{6} \mathrm{Calu}-3$ with a mean volume of $161 \pm 15 \mathrm{~mm}^{3}$ (Figure $5 \mathrm{C}$ ) and 

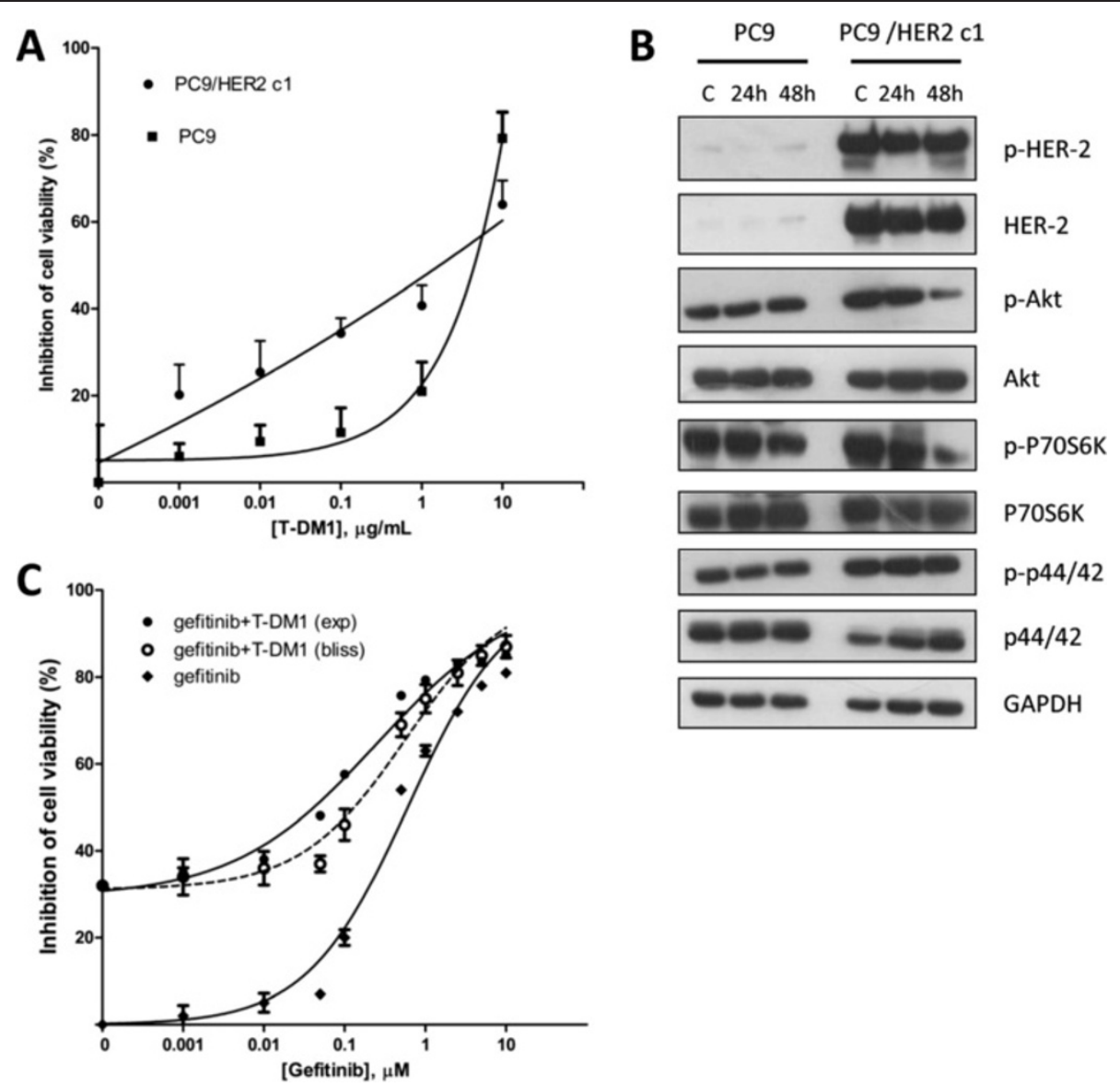

Figure 4 Effect of T-DM1 on EGFR-mutant PC9 cell line become resistant to gefitinib for HER-2 overexpression. (A) PC9 and PC9/HER2 C1 cells were exposed to increasing concentrations of T-DM1 for $72 \mathrm{~h}$ and then cell viability was assessed by MTT assay. Data are expressed as mean + SD of three different experiments. (B) Immunoblot analysis of proteins of signalling transduction pathways were conducted on cell lysates obtained after treatment with T-DM1 $(1 \mathrm{\mu g} / \mathrm{ml})$ for 24 or $48 \mathrm{~h}$. (C) Curves of growth inhibitory effects of gefitinib and combined treatment gefitinib plus T-DM1 versus theoretical Bliss additivity curve are reported. Cells were treated with the drugs for $72 \mathrm{~h}$ and then cell number was assessed by MTT assy. Data are expressed as percent inhibition of cell proliferation versus control cells. The experiments, repeated three times, yielded similar results.

$370 \pm 50 \mathrm{~mm}^{3}$ (Figure 5D) respectively. Trastuzumab (15 mg/Kg intraperitoneal) or T-DM1 (15 mg/Kg intravenously) were given every six days. T-DM1 or trastuzumab treatments in animals carrying tumors of small size were able to strongly inhibit tumor growth compared to vehicle treated mice (Figure 5C). Treatment with T-DM1 not only inhibited tumor growth, but a reduction of tumor dimension was observed in five out of six mice.

On the other hand, when treatments were performed on larger tumors, only T-DM1 was able to significantly reduce tumor growth compared to control group, whereas no significant effect was seen with trastuzumab (Figure 5D). We did observe neither rapid tumor shrinkage nor long term complete response in T-DM1 treated animals. T-DM1 in vivo efficacy was confirmed by the reduction in weight of tumors excised at sacrifice, compared to control (Inset to Figure 5C and D).

To define at tissue level the response of small and large tumors to T-DM1, a morphometric analysis of neoplastic tissue composition was performed. To this purpose, the fractional volume occupied by $\mathrm{PanCK}^{\text {pos }}$ cells was assessed (Figure 6A,B). Quantitatively, compared to control in small tumors a $67 \%$ and $73 \%$ reduction of neoplastic epithelial cells within the nodules was observed with trastuzumab and T-DM1, respectively (A). In large tumors, the amount of neoplastic tissue was reduced by $16 \%$ and $37 \%$, respectively, with trastuzumab and T-DM1 compared to control (B). Importantly, both drugs significantly decreased mitotic index in small and large tumors, however, the antiproliferative activity of T-DM1 was superior to that of trastuzumab (data not shown). To gain insights on the mechanism underlying these effects of T-DM1, we sought to determine whether the results obtained in vitro on the different sensitivity to T-DM1 according to cell density and HER-2 expression had an in vivo counterpart. To this hand, sections of small and large tumors were immunostained with HER-2 antibodies (Figure 6C,D). Again, differences in 

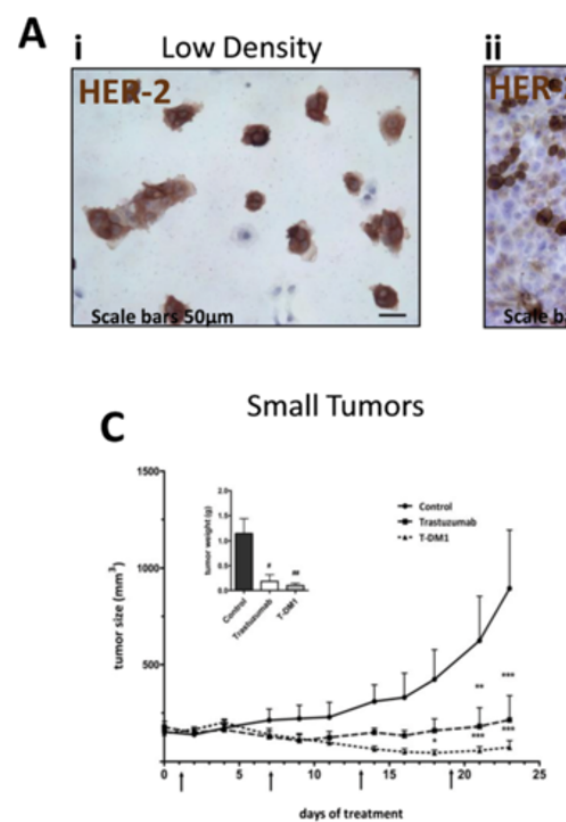

B

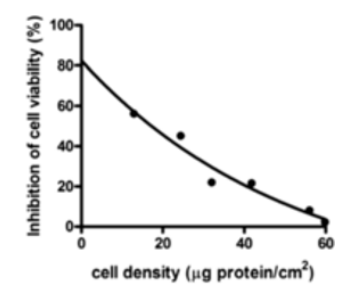

Large Tumors

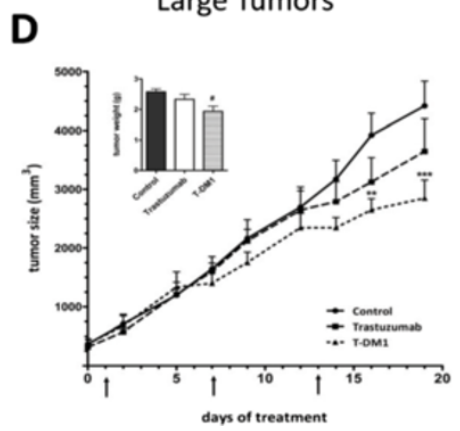

Figure 5 Cell density in vitro and tumor size in vivo influenced HER-2 expression and efficacy of T-DM1. (A) Calu-3 cells were plated at low $\left(10^{4} \mathrm{cells} / \mathrm{cm}^{2}\right)$ (i) and high $\left(8 \times 10^{4} \mathrm{cell} / \mathrm{s} / \mathrm{cm}^{2}\right)$ (ii) density and after $24 \mathrm{~h}$ membrane HER-2 protein expression was evaluated by immunohistochemistry. (B) Calu-3 cells were plated at different density and exposed for $72 \mathrm{~h}$ to T-DM1 $1 \mu \mathrm{g} / \mathrm{ml}$ and then cell number was assessed using crystal violet staining as described in Methods section. Percent inhibition of cell proliferation versus control cells was plotted as function of cell density. The experiments, repeated three times, yielded similar results. $4 \times 10^{6}$ (C) or $8 \times 10^{6}$ (D) Calu-3 cells were subcutaneously implanted on BALB/C-Nude mice. At the beginning of the treatments average tumor volumes were $161 \pm 15 \mathrm{~mm}^{3}$ and $370 \pm 50 \mathrm{~mm}^{3}$ respectively. In both settings vehicle, trastuzumab (15 mg/Kg i.p.) or T-DM1 (15 mg/Kg i.v.) were administered every six days as pointed (arrows). Tumor sizes were measured three times per week and data expressed as volume + SEM ( $n=6$ mice per group). (** $p<0.01,{ }^{* * *} p<0.001$ vs control; two-way ANOVA followed by Bonferroni's post-test). After sacrifice tumors were excised and weighted (\# $\mathrm{p}<0.05 \# \# \mathrm{p}<0.01$; one-way Anova followed by Tukey's post-test).

the surface expression of the HER-2 was striking, as neoplastic cells composing small tumors $(\mathrm{C})$ showed higher extent and intensity of HER 2 immunolabelling than large tumors (D). Thus, our data clearly document that the anti-tumor potency of T-DM1 is strictly dependent on HER-2 expression, which in turn is intrinsically modulated among neoplastic cells and their structural organization. Characteristic and atypical mitotic figures and giant multinucleated cells were detected both morphologically on HER-2 $2^{\text {pos }}$ cells (Figure 6E,F,G,H) and by the nuclear labelling of $\mathrm{PH}-\mathrm{H} 3$ in PanCK expressing cells (Figure 6I,J,K) both in small (Figure 6E,F,G,H) and large tumors (not shown).

\section{Discussion}

One of the major findings of our study is that targeting HER-2 with Trastuzumab-DM1, an antibody-drug conjugate developed to improve the treatment of HER-2 positive breast cancer, may offer a new therapeutic approach in lung cancers expressing HER-2 even when resistant to EGFR TKIs. We also demonstrated that HER-2 is highly expressed in low density NSCLC cells in vitro and in small tumors in vivo by which mechanism T-DM1 exerts a stronger efficacy.
The involvement of HER-2 in lung carcinogenesis has been known for many years but clinical research was slowed down after the negative outcome of the initial clinical trials with trastuzumab plus chemotherapy in patients with HER-2-immunohistochemistry positive NSCLC [27,28].

HER-2 protein overexpression are reported in 2-9\% (IHC 3+) [29-32] and 20\% (IHC 2+) [29-31] and gene amplification are reported in 2-20\% of NSCLC [30-32]. Moreover, HER-2 amplification was present in 13\% of the cases at the time of resistance to EGFR TKI [11]. The role of HER-2 overexpression and amplification in lung cancer remains controversial. In a meta-analysis of 40 studies in NSCLC, HER-2 overexpression assessed by IHC was associated with poor prognosis, specifically in adenocarcinomas [33]. Conversely, HER-2 amplification determined by FISH had no prognostic role [33]. HER-2 mutations are present in about $2-4 \%$ of NSCLC, especially in women, never-smokers, Asian patients and in adenocarcinomas without EGFR or K-RAS mutations [34-38]. In a population of EGFR/K-RAS/ALK-mutation negative patients, HER-2 mutations can reach up to $6 \%$ [34].

T-DM1 has been extensively studied in preclinical models of breast cancer $[15,18]$ These studies demonstrated that T-DM1 has dual mechanisms of action: 

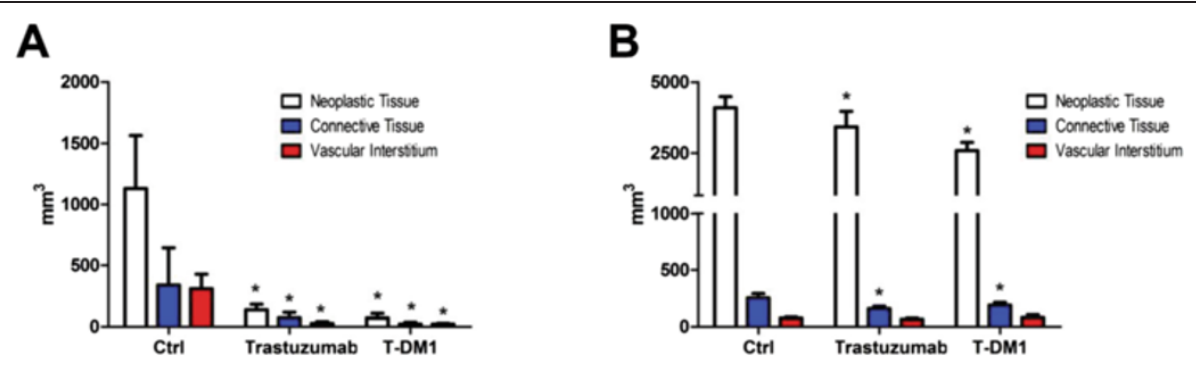

HER-2
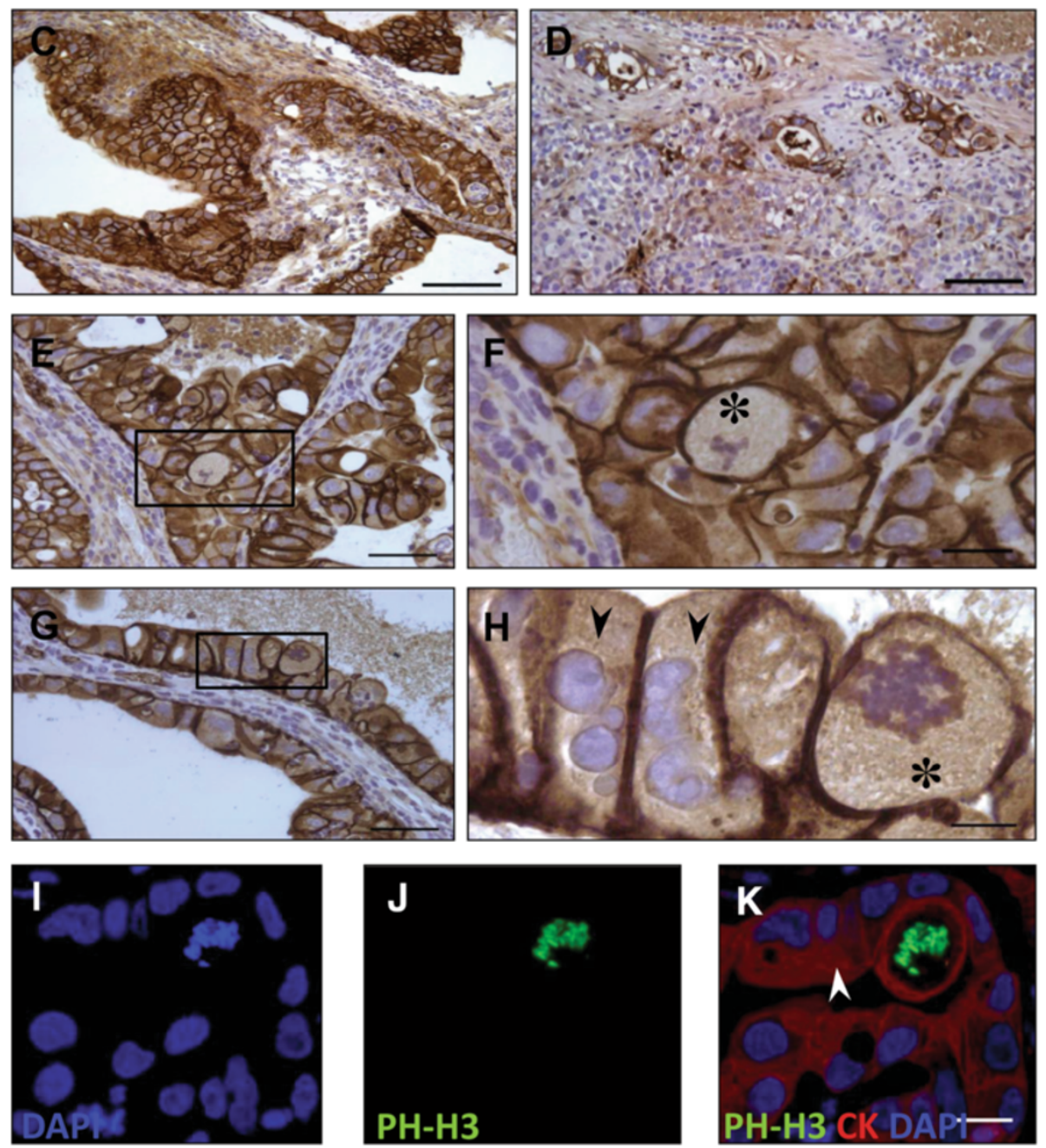

Figure 6 Neoplastic tissue composition and HER-2 expression in small and large tumors. Quantification of tissue composition in small (A) and large (B) tumour xenografts in untreated (CTRL) and Trastuzumab or T-DM1 treated mice $\left({ }^{*} p<0.05\right.$, vs control) was evaluated as described in Methods Section. C-H: Immunoperoxidase staining of xenografts by anti-HER-2 antibodies. The sharp difference in HER-2 expression (brownish) by neoplastic cells composing small (C) and large (D) tumours is apparent. $\mathbf{E}$ and $\mathbf{G}$ illustrate sections of small T-DM1 treated tumour xenografts in which black rectangles include a microscopic field shown at higher magnification in $\mathbf{F}$ and $\mathbf{H}$, respectively, to document giant mitotic figures $(*)$ on $\mathrm{HER}-2$ labeled cells. Arrows indicate polynucleated HER-2 positive neoplastic cells. The lower panels show the specific immunofluorescent labeling of metaphase chromosomes (I) by phospho-Histone $\mathrm{H3}(\mathrm{PH}-\mathrm{H} 3$, green, $\mathbf{J})$ on a large cytokeratin (CK, red, $\mathbf{K})$ positive cell. Arrow points to a giant polynucleated neoplastic cell. Scale bars: C, D =100 $\mu \mathrm{m} ; \mathrm{E}, \mathrm{G}=50 \mu \mathrm{m} ; \mathrm{F}, \mathrm{I}, \mathrm{L}, \mathrm{M}=20 \mu \mathrm{m}$ and $\mathrm{H}=10 \mu \mathrm{m}$. 
selective delivery of DM1 to the HER-2-positive tumor cells and activation of antibody-dependent cellular cytotoxicity. T-DM1 demonstrated activity in both trastuzumab and lapatinib resistant HER-2 positive cancer models [18]. T-DM1 was effective also in gastric cell lines [22] and antiproliferative properties have been reported in ovarian SK-OV-3 cell line and in the NSCLC Calu-3 cell line and xenografts [39].

In a recent review Landi and Cappuzzo [40] hypothesized that T-DM1 could play an important role even in NSCLC, and underlined the need of a proper investigation of the real impact of T-DM1 in lung cancer.

All the above observations prompted us to investigate, in a panel of NSCLC cell lines with different levels of HER-2 expression or carrying HER-2 mutation, the effect of T-DM1 on cell proliferation and survival.

In agreement with previously reported data in breast cancer models [15], we documented that also in NSCLC cell lines T-DM1 efficiently inhibited proliferation with arrest in G2-M phase. Moreover, T-DM1 induced cell death by apoptosis in cells with a significant level of surface expression of HER-2 while cells with low level of HER-2 failed to respond to the drug. Interestingly, trastuzumab did not inhibit cell proliferation irrespective of HER-2 expression. H1781 cell line, harbouring mutated HER-2 (G776insV_G/C), was also included in our study. The effect of T-DM1 in this cell line was presumably related to HER-2 level and not affected by the presence of the mutation. Antibody-dependent cytotoxicity assay performed with NK cells demonstrated that T-DM1 retained the activity of trastuzumab as previously reported in breast and gastric models [18,22]. Moreover, we demonstrated that T-DM1 is able to inhibit the growth of a EGFR mutant cell line in which HER-2 overexpression confers resistance to gefitinib. Therefore, targeting HER-2 with T-DM1 might represent a potential approach to overcome EFGR-TKI resistance.

Our in vitro and in vivo experiments documented that, respectively, low cell density and small xenografted tumors were associated with higher HER-2 expression and thereby greater T-DM1 sensitivity. Thus, the present investigation strongly support the contention that HER-2 expression in NSCLC is regulated by the tumor mass and its structural organization which in turn condition the efficacy of T-DM1. Finally, we suggest that the expression level of HER-2, determined by immunohistochemistry, might represent a predictive factor of response to T-DM1 in tumors carrying wild type or mutant HER-2 receptor.

\section{Conclusions}

Our results indicate that T-DM1 inhibited cell proliferation and induced apoptosis in NSCLC cells with endogenous or acquired high HER-2 levels but its activity does not seem to be related to HER-2 mutational status.
Moreover, a correlation between cell density/tumour size with both HER-2 expression and T-DM1 activity was established in vitro and in an in vivo xenograft model.

In conclusion, dual-agent molecular targeting through T-DM1 may be a promising therapy in HER-2 positive lung cancer even in tumors which had developed resistance to EGFR-TKIs.

\section{Methods}

\section{Cell culture}

The human NSCLC cell lines used in this study were purchased from American Type Culture Collection (ATCC) (Manassas, VA, USA) and banked at early passage (P2). Furthermore, the cells we culture, are regularly verified on the basis of cell morphology and never cultured for more than 3 months. The PC9, HCC827, HCC827 GR5 and H1781 cell lines were kindly provided in 2013 by Dr P. Jänne (Dana-Farber Cancer Institute, Boston MA, USA). The PC9/HER2c1 was kindly provided in 2013 by Dr.William Pao (Vanderbilt-Ingram Cancer Center, Nashville, Tennessee). All cells were cultured as recommended and maintained at $37^{\circ} \mathrm{C}$ in a humidified atmosphere of $5 \% \mathrm{CO}_{2}$ and $95 \%$ air.

\section{Drugs}

Trastuzumab and vinorelbine were kindly provided by inpatient pharmacy. T-DM1 was supplied from Genentech Inc. (South San Francisco, CA) through a Materials Transfer Agreement. For the in vitro experiments, stock solutions of drugs were prepared in distilled water, stored at $4^{\circ} \mathrm{C}$ and diluted in fresh medium for use, whereas for the in vivo experiments trastuzumab and T-DM1 were daily dissolved in sterile saline solution $(\mathrm{NaCl} 0.9 \%)$.

\section{Western immunoblot analysis}

Cell protein extraction, solubilization, and analysis by 1-D PAGE were performed as previously described [41]. Antibodies against HER2; p-HER2 Tyr1221/1222; p70S6K;

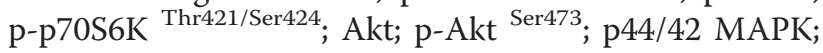
p-p44/42 MAPK; caspase-7 and 9; cyclin A and B1; $\mathrm{Rb}$; $\mathrm{p}-\mathrm{Rb}$ were from Cell Signaling Technology (Beverly, MA). Antibody against cytochrome-c (7H8) was form Santa Cruz Biotechnology Inc. (Dallas, TX). Antibodies against actin was from Sigma-Aldrich (St Louis, MO). Antibody against GAPDH was from Ambion (Austin, TX). HRP-conjugated secondary antibodies were from Pierce (Rockford, IL) and chemiluminescence system (ImmobilionTM Western Cemiluminescent HRP Substrate), was from Millipore (Temecula, CA).

\section{Flow cytometry}

One million of NSCLC cell lines were incubated, for one hour at room temperature, with Isotype control Monoclonal Mouse IgG1/R-PE (Ancell IRP, Bayport, 
MN, USA) or PE mouse anti-Human HER-2 (BD Biosciences, San Josè CA) to determine HER-2 protein membrane levels as previously described [42]. After the incubation the analysis was performed using an EPICS-XL flow cytometer. Mean fluorescence intensity (MFI) values were converted in units of equivalent fluorochrome (MEF) using the FluoroSpheres 6-Peak Kit (Dako, CA, USA).

\section{Analysis of cell proliferation and cell cycle}

Cell viability was evaluated by tetrazolium dye [3-(4,5-dimethylthiazol-2-yl)-2,5-diphenyltetrazolium- bromide] (MTT) assay and by crystal violet staining as previously described [43]. Data are expressed as percent inhibition of cell proliferation versus control cells. Distribution of the cells in the cell cycle was determined by PI staining and flow cytometry analysis as described elsewhere [44].

\section{Detection of apoptosis}

Apoptosis was assessed by morphological study: stained (Hoechst 33342, propidium iodide) or unstained cells were observed using light-, phase-contrast- and fluorescencemicroscopy. Western blot analysis was performed to evaluate cleavage products of caspase- 7 and caspase- 9 . Cytosolic and mitochondrial fractions for cytochrome- $c$ detection were generated using a digitonin-based subcellular fractionation technique as previously described [45].

\section{Isolation and culture of NK cells and ADCC assay}

Highly purified CD56+ natural killer (NK) cells were obtained by magnetic separation and ADCC was measured with the CytoTox 96 non-radioactive cytotoxicity assay (Promega, Madison, WI, USA) as previously described [42].

\section{Tumor xenografts}

All experiments involving animals and their care were performed with the approval of the Local Ethical Committee of the University of Parma, in accordance with the institutional guidelines that are in compliance with national (DL116/92) and international (86/609/CEE) laws and policies.

Balb/c-Nude female mice (Charles River Laboratories, Calco, Italy) 6 weeks old, were housed in a protected unit for immunodeficient animals with 12-hour light/ dark cycles and provided with sterilized food and water ad libitum [41,42]. We performed an in vivo experiment in order to investigate whether the tumor dimension could influence drug efficacy. $200 \mu \mathrm{l}$ of matrigel (BD Biosciences) and sterile PBS (1:1) containing $4 \times 10^{6}$ or $8 \times 10^{6}$ Calu-3 cells were subcutaneously injected on the right flank of each mouse. Ten days after cells injection, tumor volume reached an average size of $160 \mathrm{~mm}^{3}$ or $370 \mathrm{~mm}^{3}$ respectively, and animals were randomized into three different groups $(n=6)$ : control, trastuzumab and T-DM1. Once every six days trastuzumab was intraperitoneally administered at a dosage of $15 \mathrm{mg} / \mathrm{Kg}$, whereas T-DM1 was injected into the lateral tail vein at a dosage of $15 \mathrm{mg} / \mathrm{Kg}$. Control mice received intravenous injection of sterile saline solution $(\mathrm{NaCl} 0.9 \%)$ according to the same schedule. Drug dosages were chosen accordingly to previous studies conducted on breast and gastric xenograft models [15,17,18,22].

Tumor xenografts were measured three times per week using a digital caliper and tumor volume was determined using the formula: (length $\times$ width $^{2}$ )/2. At the end of the experiments, mice were euthanized by cervical dislocation and tumors weighted and collected for immunohistochemical and histological analysis.

\section{Morphometric and immunohistochemical analysis of tumor xenografts}

Formalin fixed samples were embedded in paraffin. On each tumor serial sections of $5 \mu \mathrm{m}$ thickness were stained with Haematoxylin and Eosin (H\&E), Masson's Trichrome and subjected to immunohistochemistry. A morphometric analysis was performed on the entire section in order to evaluate the volume of neoplastic tissue, connective tissue and vascular interstitium. To better define the fraction occupied by neoplastic cells, sections were stained with pancytokeratin antibody (PanCK monoclonal mouse, 1:500, o.n. $4^{\circ} \mathrm{C}$, Dako) revealed through biotin-streptavidin-DAB system (Dako). The volume fraction of fibrosis and vascular interstitium was assessed on Masson's Trichrome stained samples. To this end, the number of points overlying each tissue components was counted and expressed as percentage of the total number of points explored. All these morphometric measurements were obtained with the aid of a grid defining a tissue area of $0.23 \mathrm{~mm}^{2}$ and containing 42 sampling points each covering an area of $0.0052 \mathrm{~mm}^{2}$.

Combining the entire tumor volume with the above morphometric measurements, the total volume occupied by neoplastic cells, connective tissue and vascular interstitium was computed for each sample.

Moreover, immunohistochemical analysis of HER-2 was performed on each tumor of each experimental group. Sections were stained with HER-2 antibody (monoclonal mouse clone 4B5, Ventana, USA) and revealed through biotin-streptavidin-DAB system. This analysis was performed on the entire tumor by an optical microscope (Olympus, BX60-100X magnification) to evaluate the area occupied by cell expressing HER-2 and their intensity. The latter was expressed as Integrated Optical density (IOD), as detected using a software for image analysis (Image Pro Plus, Media Cybernetics, USA).

In addition, the nuclear expression of the phosphorylated form of Histone $\mathrm{H} 3$ ( $\mathrm{pH}-\mathrm{H} 3$, rabbit poyclonal, 1:100, Millipore, USA) on Pancytokeratin ${ }^{\text {pos }}$ cells was detected by immunofluorescence to document mitotic figures. 
For all tested epitopes negative controls were represented by immunostaining the sample with an irrelevant antibody or by exposing the sections only to the secondary antibody.

\section{Statistical analysis}

Statistical analyses were carried out using GraphPad Prism version 5.0 software (GraphPad Software Inc., San Diego, CA, USA). Results are expressed as mean values \pm standard deviations (SD) for the indicated number of independent measurements. Differences between the mean values recorded for different experimental conditions were evaluated by Student's $t$ test, and P values are indicated where appropriate in the figures and in their legends. A P value $<0.05$ was considered as significant. Bliss interaction was calculated as previously described [46]. For in vivo studies comparison among groups was made using analysis of variance (two-way ANOVA repeated measures) followed by Bonferroni's post-test.

\section{Abbreviations}

ADCC: Antibody-dependent cellular-cytotoxicity; EGFR: Epidermal growth factor receptor; NSCLC: Non small cell lung cancer; TKl: Tyrosine kinase inhibitor.

\section{Competing interests}

All authors declare that they have no competing interests.

\section{Authors' contribution}

DC carried out flow cytometry, cell cycle, experiments on resistant clone and analyzed the results; FS performed the in vivo studies, interpreted the results and performed the statistical analysis; FQ, CF and GG carried out morphometric and immunohistochemical analysis; MB carried out Western blot analysis; CF evaluated cell death; AC isolated and cultured NK cells and carried out ADCC experiments; SLM, MG and CC carried out cell growth experiments; LA was responsible for drug administration in in vivo studies; MT, AA and PGP critically revised the manuscript and assisted with the draft of the manuscript; RRA, designed the project, analyzed the results and wrote the manuscript. All authors read and approved the final manuscript.

\section{Acknowledgements}

This work was supported by Associazione Italiana per la Ricerca sul Cancro (AIRC), Milan grant IG 8856; A.VO.PRO.RI.T., Parma, Associazione Augusto per la Vita (Novellara, RE); Associazione Davide Rodella, Montichiari, BS;

Associazione Chiara Tassoni, Parma.

Technical assistance: Gabriella Becchi and Emilia Corradini.

\section{Author details \\ ${ }^{1}$ Department of Clinical and Experimental Medicine, University of Parma, Via Gramsci 14, 43126 Parma, Italy. ${ }^{2}$ Department of Biomedical, Biotechnological and Translational Sciences, University of Parma, Parma, Italy. I'talian Workers' Compensation Authority (INAIL) Research Centre at the University of Parma, Parma, Italy. ${ }^{4}$ Thoracic Surgery, Department of Surgical Science, University Hospital of Parma, Parma, Italy. Division of Medical Oncology, University Hospital of Parma, Parma, Italy.}

Received: 7 April 2014 Accepted: 30 May 2014 Published: 5 June 2014

\section{References}

1. Oxnard GR, Lo PC, Nishino M, Dahlberg SE, Lindeman NI, Butaney M Jackman DM, Johnson BE, Janne PA: Natural history and molecular characteristics of lung cancers harboring EGFR exon 20 insertions. J Thorac Oncol 2013, 8:179-184.

2. Mok TS, Wu YL, Thongprasert S, Yang CH, Chu DT, Saijo N, Sunpaweravong P, Han B, Margono B, Ichinose Y, Nishiwaki Y, Ohe Y, Yang JJ,
Chewaskulyong B, Jiang H, Duffield EL, Watkins CL, Armour AA, Fukuoka M: Gefitinib or carboplatin-paclitaxel in pulmonary adenocarcinoma. N Engl $J$ Med 2009, 361:947-957.

3. Rosell R, Carcereny E, Gervais R, Vergnenegre A, Massuti B, Felip E, Palmero R, Garcia-Gomez R, Pallares C, Sanchez JM, Porta R, Cobo M, Garrido P, Longo F, Moran T, Insa A, De Marinis F, Corre R, Bover I, Illiano A, Dansin E, de Castro J, Milella M, Reguart N, Altavilla G, Jimenez U, Provencio M, Moreno MA, Terrasa J, Muñoz-Langa J: Erlotinib versus standard chemotherapy as first-line treatment for European patients with advanced EGFR mutation-positive non-small-cell lung cancer (EURTAC): a multicentre, open-label, randomised phase 3 trial. Lancet Oncol 2012, 13:239-246.

4. Sequist LV, Yang JC, Yamamoto N, O'Byrne K, Hirsh V, Mok T, Geater SL, Orlov S, Tsai CM, Boyer M, Su WC, Bennouna J, Kato T, Gorbunova V, Lee KH, Shah R, Massey D, Zazulina V, Shahidi M, Schuler M: Phase III study of afatinib or cisplatin plus pemetrexed in patients with metastatic lung adenocarcinoma with EGFR mutations. J Clin Oncol 2013, 31:3327-3334.

5. Shaw AT, Kim DW, Nakagawa K, Seto T, Crino L, Ahn MJ, De Pas T, Besse B, Solomon BJ, Blackhall F, Wu YL, Thomas M, O'Byrne KJ, Moro-Sibilot D, Camidge DR, Mok T, Hirsh V, Riely GJ, Iyer S, Tassell V, Polli A, Wilner KD, Jänne PA: Crizotinib versus chemotherapy in advanced ALK-positive lung cancer. N Engl J Med 2013, 368:2385-2394.

6. Gandhi L, Janne PA: Crizotinib for ALK-rearranged non-small cell lung cancer: a new targeted therapy for a new target. Clin Cancer Res 2012, 18:3737-3742

7. Sequist $L V$, Waltman $B A$, Dias-Santagata $D$, Digumarthy $S$, Turke $A B$, Fidias $P$, Bergethon K, Shaw AT, Gettinger S, Cosper AK, Akhavanfard S, Heist RS, Temel J, Christensen JG, Wain JC, Lynch TJ, Vernovsky K, Mark EJ, Lanuti M, lafrate AJ, Mino-Kenudson M, Engelman JA: Genotypic and histological evolution of lung cancers acquiring resistance to EGFR inhibitors. Sci Transl Med 2011, 3:75ra26.

8. Pao W, Miller VA, Politi KA, Riely GJ, Somwar R, Zakowski MF, Kris MG, Varmus $\mathrm{H}$ : Acquired resistance of lung adenocarcinomas to gefitinib or erlotinib is associated with a second mutation in the EGFR kinase domain. PLoS Med 2005, 2:e73.

9. Engelman JA, Zejnullahu K, Mitsudomi T, Song Y, Hyland C, Park JO, Lindeman N, Gale CM, Zhao X, Christensen J, Kosaka T, Holmes AJ, Rogers AM, Cappuzzo F, Mok T, Lee C, Johnson BE, Cantley LC, Jänne PA: MET amplification leads to gefitinib resistance in lung cancer by activating ERBB3 signaling. Science 2007, 316:1039-1043.

10. Oxnard GR, Arcila ME, Sima CS, Riely GJ, Chmielecki J, Kris MG, Pao W, Ladanyi M, Miller VA: Acquired resistance to EGFR tyrosine kinase inhibitors in EGFR-mutant lung cancer: distinct natural history of patients with tumors harboring the T790M mutation. Clin Cancer Res 2011, 17:1616-1622.

11. Yu HA, Arcila ME, Rekhtman N, Sima CS, Zakowski MF, Pao W, Kris MG, Miller VA, Ladanyi M, Riely GJ: Analysis of tumor specimens at the time of acquired resistance to EGFR-TKI therapy in 155 patients with EGFR-mutant lung cancers. Clin Cancer Res 2013, 19:2240-2247.

12. Gainor JF, Shaw AT: Emerging paradigms in the development of resistance to tyrosine kinase inhibitors in lung cancer. $J$ Clin Oncol 2013, 31:3987-3996.

13. Cagle PT, Chirieac LR: Advances in treatment of lung cancer with targeted therapy. Arch Pathol Lab Med 2012, 136:504-509.

14. Takezawa K, Pirazzoli V, Arcila ME, Nebhan CA, Song X, De Stanchina E, Ohashi K, Janjigian YY, Spitzler PJ, Melnick MA, Riely GJ, Kris MG, Miller VA, Ladanyi M, Politi K, Pao W: HER2 amplification: a potential mechanism of acquired resistance to EGFR inhibition in EGFR-mutant lung cancers that lack the second-site EGFRT790M mutation. Cancer Discov 2012, 2:922-933.

15. Lewis Phillips GD, Li G, Dugger DL, Crocker LM, Parsons KL, Mai E, Blattler WA, Lambert JM, Chari RV, Lutz RJ, Wong WL, Jacobson FS, Koeppen H, Schwall RH, Kenkare-Mitra SR, Spencer SD, Sliwkowski MX: Targeting HER2positive breast cancer with trastuzumab-DM1, an antibody-cytotoxic drug conjugate. Cancer Res 2008, 68:9280-9290.

16. Oroudjev E, Lopus M, Wilson L, Audette C, Provenzano C, Erickson H, Kovtun Y, Chari R, Jordan MA: Maytansinoid-antibody conjugates induce mitotic arrest by suppressing microtubule dynamic instability. Mol Cancer Ther 2010, 9:2700-2713.

17. Barok M, Tanner M, Koninki K, Isola J: Trastuzumab-DM1 causes tumour growth inhibition by mitotic catastrophe in trastuzumab-resistant breast cancer cells in vivo. Breast Cancer Res 2011, 13:R46.

18. Junttila TT, Li G, Parsons K, Phillips GL, Sliwkowski MX: Trastuzumab-DM1 (T-DM1) retains all the mechanisms of action of trastuzumab and 
efficiently inhibits growth of lapatinib insensitive breast cancer. Breast Cancer Res Treat 2011, 128:347-356.

19. Verma S, Miles D, Gianni L, Krop IE, Welslau M, Baselga J, Pegram M, Oh DY, Dieras V, Guardino E, Fang L, Lu MW, Olsen S, Blackwell K: Trastuzumab emtansine for HER2-positive advanced breast cancer. N Engl J Med 2012, 367:1783-1791.

20. Engelman JA, Zejnullahu K, Gale CM, Lifshits E, Gonzales AJ, Shimamura T, Zhao F, Vincent PW, Naumov GN, Bradner JE, Althaus IW, Gandhi L, Shapiro Gl, Nelson JM, Heymach JV, Meyerson M, Wong KK, Jänne PA: PF00299804, an irreversible pan-ERBB inhibitor, is effective in lung cancer models with EGFR and ERBB2 mutations that are resistant to gefitinib. Cancer Res 2007, 67:11924-11932.

21. Minami Y, Shimamura T, Shah K, LaFramboise T, Glatt KA, Liniker E, Borgman CL, Haringsma HJ, Feng W, Weir BA, Lowell AM, Lee JC, Wolf J, Shapiro Gl, Wong KK, Meyerson M, Thomas RK: The major lung cancer-derived mutants of ERBB2 are oncogenic and are associated with sensitivity to the irreversible EGFR/ERBB2 inhibitor HKI-272. Oncogene 2007, 26:5023-5027.

22. Barok M, Tanner M, Koninki K, Isola J: Trastuzumab-DM1 is highly effective in preclinical models of HER2-positive gastric cancer. Cancer Lett 2011, 306:171-179.

23. Clynes RA, Towers TL, Presta LG, Ravetch JV: Inhibitory Fc receptors modulate in vivo cytotoxicity against tumor targets. Nat Med 2000, 6:443-446.

24. Hamburger AW, Mehta D, Pinnamaneni G, Chen LC, Reid Y: Density-dependent regulation of epidermal growth factor receptor expression. Pathobiology 1991, 59:329-334.

25. Olszewski-Hamilton U, Hamilton G: Dependence of relative expression of NTR1 and EGFR on cell density and extracellular pH in human pancreatic cancer cell lines. Cancers (Basel) 2011, 3:182-197.

26. Kornilova ES, Taverna D, Hoeck W, Hynes NE: Surface expression of erbB-2 protein is post-transcriptionally regulated in mammary epithelial cells by epidermal growth factor and by the culture density. Oncogene 1992 7:511-519.

27. Gatzemeier U, Groth G, Butts C, Van Zandwijk N, Shepherd F, Ardizzoni A, Barton C, Ghahramani P, Hirsh V: Randomized phase II trial of gemcitabine-cisplatin with or without trastuzumab in HER2-positive non-small-cell lung cancer. Ann Oncol 2004, 15:19-27.

28. Lara PN Jr, Laptalo L, Longmate J, Lau DH, Gandour-Edwards R, Gumerlock PH, Doroshow JH, Gandara DR: Trastuzumab plus docetaxel in HER2/neupositive non-small-cell lung cancer: a California Cancer Consortium screening and phase II trial. Clin Lung Cancer 2004, 5:231-236.

29. Langer CJ, Stephenson P, Thor A, Vangel M, Johnson DH: Trastuzumab in the treatment of advanced non-small-cell lung cancer: is there a role? Focus on Eastern Cooperative Oncology Group study 2598. J Clin Oncol 2004, 22:1180-1187.

30. Pellegrini C, Falleni M, Marchetti A, Cassani B, Miozzo M, Buttitta F, Roncalli $M$, Coggi G, Bosari S: HER-2/Neu alterations in non-small cell lung cancer: a comprehensive evaluation by real time reverse transcription-PCR, fluorescence in situ hybridization, and immunohistochemistry. Clin Cancer Res 2003, 9:3645-3652.

31. Heinmoller P, Gross C, Beyser K, Schmidtgen C, Maass G, Pedrocchi M, Ruschoff J: HER2 status in non-small cell lung cancer: results from patient screening for enrollment to a phase II study of herceptin. Clin Cancer Res 2003, 9:5238-5243.

32. Yan M, Parker BA, Schwab R, Kurzrock R: HER2 aberrations in cancer: implications for therapy. Cancer Treat Rev 2014, 40:770-780.

33. Liu L, Shao X, Gao W, Bai J, Wang R, Huang P, Yin Y, Liu P, Shu Y: The role of human epidermal growth factor receptor 2 as a prognostic factor in lung cancer: a meta-analysis of published data. J Thorac Oncol 2010, 5:1922-1932.

34. Arcila ME, Chaft JE, Nafa K, Roy-Chowdhuri S, Lau C, Zaidinski M, Paik PK, Zakowski MF, Kris MG, Ladanyi M: Prevalence, clinicopathologic associations, and molecular spectrum of ERBB2 (HER2) tyrosine kinase mutations in lung adenocarcinomas. Clin Cancer Res 2012, 18:4910-4918.

35. Mazieres J, Peters S, Lepage B, Cortot AB, Barlesi F, Beau-Faller M, Besse B, Blons H, Mansuet-Lupo A, Urban T, Moro-Sibilot D, Dansin E, Chouaid C, Wislez M, Diebold J, Felip E, Rouquette I, Milia JD, Gautschi O: Lung cancer that harbors an HER2 mutation: epidemiologic characteristics and therapeutic perspectives. J Clin Oncol 2013, 31:1997-2003.
36. Nicos M, Krawczyk P, Mlak R, Sawicki M, Jarosz B, Powrozek T, Milanowski P, Trojanowski T, Milanowski J: The presence of HER2 exon 20 insertion in patients with central nervous system metastases from non-small lung cancer-a potential application in classification for therapy. Pneumonol Alergol Pol 2013, 81:294-297.

37. Tomizawa K, Suda K, Onozato R, Kosaka T, Endoh H, Sekido Y, Shigematsu $\mathrm{H}$, Kuwano H, Yatabe Y, Mitsudomi T: Prognostic and predictive implications of HER2/ERBB2/neu gene mutations in lung cancers. Lung Cancer 2011, 74:139-144.

38. Stephens $P$, Hunter $C$, Bignell $G$, Edkins $S$, Davies $H$, Teague J, Stevens $C$, O'Meara S, Smith R, Parker A, Barthorpe A, Blow M, Brackenbury L, Butler A, Clarke O, Cole J, Dicks E, Dike A, Drozd A, Edwards K, Forbes S, Foster R, Gray K, Greenman C, Halliday K, Hills K, Kosmidou V, Lugg R, Menzies A, Perry J, et al: Lung cancer: intragenic ERBB2 kinase mutations in tumours. Nature 2004, 431:525-526.

39. Phillips GD, Fields $C T$, Li G, Dowbenko D, Schaefer G, Miller K, Andre F, Burris HA 3rd, Albain KS, Harbeck N, Dieras V, Crivellari D, Fang L, Guardino E, Olsen SR, Crocker LM, Sliwkowski MX: Dual targeting of HER2-positive cancer with trastuzumab emtansine and pertuzumab: critical role for neuregulin blockade in antitumor response to combination therapy. Clin Cancer Res 2014, 20:456-468.

40. Landi L, Cappuzzo F: HER2 and lung cancer. Expert Rev Anticancer Ther 2013, 13:1219-1228.

41. Galvani E, Giovannetti E, Saccani F, Cavazzoni A, Leon LG, Dekker H, Alfieri R, Carmi C, Mor M, Ardizzoni A, Petronini PG, Peters GJ: Molecular mechanisms underlying the antitumor activity of 3-aminopropanamide irreversible inhibitors of the epidermal growth factor receptor in non-small cell lung cancer. Neoplasia 2013, 15:61-72.

42. Cavazzoni A, Alfieri RR, Cretella D, Saccani F, Ampollini L, Galetti M, Quaini F, Graiani G, Madeddu D, Mozzoni P, Galvani E, La Monica S, Bonelli M, Fumarola C, Mutti A, Carbognani P, Tiseo M, Barocelli E, Petronini PG, Ardizzoni A: Combined use of anti-ErbB monoclonal antibodies and erlotinib enhances antibody-dependent cellular cytotoxicity of wild-type erlotinib-sensitive NSCLC cell lines. Mol Cancer 2012, 11:91.

43. Alfieri RR, Galetti M, Tramonti S, Andreoli R, Mozzoni P, Cavazzoni A, Bonelli M, Fumarola C, La Monica S, Galvani E, De Palma G, Mutti A, Mor M, Tiseo M, Mari E, Ardizzoni A, Petronini PG: Metabolism of the EGFR tyrosin kinase inhibitor gefitinib by cytochrome P450 1A1 enzyme in EGFR-wild type non small cell lung cancer cell lines. Mol Cancer 2011, 10:143.

44. La Monica S, Caffarra C, Saccani F, Galvani E, Galetti M, Fumarola C, Bonelli M, Cavazzoni A, Cretella D, Sirangelo R, Gatti R, Tiseo M, Ardizzoni A, Giovannetti E, Petronini PG, Alfieri RR: Gefitinib Inhibits Invasive Phenotype and Epithelial-Mesenchymal Transition in Drug-Resistant NSCLC Cells with MET Amplification. PLoS One 2013, 8:e78656.

45. Cavazzoni A, Alfieri RR, Carmi C, Zuliani V, Galetti M, Fumarola C, Frazzi R, Bonelli M, Bordi F, Lodola A, Mor M, Petronini PG: Dual mechanisms of action of the 5-benzylidene-hydantoin UPR1024 on lung cancer cell lines. Mol Cancer Ther 2008, 7:361-370.

46. Bonelli MA, Fumarola C, Alfieri RR, La Monica S, Cavazzoni A, Galetti M, Gatti R, Belletti S, Harris AL, Fox SB, Evans DB, Dowsett M, Martin LA, Bottini A, Generali D, Petronini PG: Synergistic activity of letrozole and sorafenib on breast cancer cells. Breast Cancer Res Treat 2010, 124:79-88.

\section{doi:10.1186/1476-4598-13-143}

Cite this article as: Cretella et al:: Trastuzumab emtansine is active on HER-2 overexpressing NSCLC cell lines and overcomes gefitinib resistance. Molecular Cancer 2014 13:143. 